Article

\title{
Intravenous Administration of Lycopene, a Tomato Extract, Protects against Myocardial Ischemia-Reperfusion Injury
}

\author{
Chao Tong ${ }^{1,2,3}$, Chuan Peng ${ }^{4}$, Lianlian Wang ${ }^{2}$, Li Zhang ${ }^{2}$, Xiaotao Yang ${ }^{2}$, Ping $\mathrm{Xu}^{2}{ }^{2}$, Jinjin $\mathrm{Li}^{2}$, \\ Thibaut Delplancke ${ }^{1,2}$, Hua Zhang ${ }^{1,2, *}$ and Hongbo Qi ${ }^{1,2, *}$ \\ 1 Department of Obstetrics, The First Affiliated Hospital of Chongqing Medical University, 1 Youyi Road, \\ Yuzhong District, Chongqing 400016, China; chaotongcqmu@163.com (C.T.); \\ thibautdelplancke@gmail.com (T.D.) \\ 2 Canada-China-New Zealand Joint Laboratory of Maternal and Fetal Medicine, Chongqing Medical \\ University, Chongqing 400016, China; llian_w@163.com (L.W.); Morcherl@163.com (L.Z.); \\ xiaotaocqmu@163.com (X.Y.); aaa.abing@foxmail.com (P.X.); shinydl@163.com (J.L.) \\ 3 Chemical Biology Research Center, College of Pharmaceutical Sciences, Wenzhou Medical University, \\ Wenzhou 325035, Zhejiang, China \\ 4 Laboratory of Lipid \& Glucose Metabolism, The First Affiliated Hospital of Chongqing Medical University, \\ Chongqing 400016, China; pengchuan2096@sina.com \\ * Correspondence: zh2844@gmail.com (H.Z.); qihongbo728@163.com (H.Q.); \\ Tel.: +86-23-8901-1102 (H.Z.); +86-23-8901-1865 (H.Q.)
}

Received: 14 January 2016; Accepted: 25 February 2016; Published: 3 March 2016

\begin{abstract}
Background: Oral uptake of lycopene has been shown to be beneficial for preventing myocardial ischemia-reperfusion (I/R) injury. However, the strong first-pass metabolism of lycopene influences its bioavailability and impedes its clinic application. In this study, we determined an intravenous (IV) administration dose of lycopene protects against myocardial infarction (MI) in a mouse model, and investigated the effects of acute lycopene administration on reactive oxygen species (ROS) production and related signaling pathways during myocardial I/R. Methods: In this study, we established both in vitro hypoxia/reoxygenation (H/R) cell model and in vivo regional myocardial $\mathrm{I} / \mathrm{R}$ mouse model by ligating left anterior artery descending. TTC dual staining was used to assess $\mathrm{I} / \mathrm{R}$ induced $\mathrm{MI}$ in the absence and presence of acute lycopene administration via tail vein injection. Results: Lycopene treatment $(1 \mu \mathrm{M})$ before reoxygenation significantly reduced cardiomyocyte death induced by $\mathrm{H} / \mathrm{R}$. Intravenous administration of lycopene to achieve $1 \mu \mathrm{M}$ concentration in circulating blood significantly suppressed MI, ROS production, and JNK phosphorylation in the cardiac tissue of mice during in vivo regional I/R. Conclusion: Elevating circulating lycopene to $1 \mu \mathrm{M}$ via IV injection protects against myocardial I/R injury through inhibition of ROS accumulation and consequent inflammation in mice.
\end{abstract}

Keywords: lycopene; ischemia-reperfusion injury; myocardial infarction; ROS; inflammation

\section{Introduction}

Ischemic heart diseases (IHD) are caused by insufficient blood and oxygen supply to the myocardium as a result of an arteriolar blockage. Angioplasty, coronary bypass surgery, and thrombolytic treatment are commonly used to treat patients with severe IHD. However, reperfusion after a period of prolonged ischemia can often cause myocardial ischemia-reperfusion (I/R) injury, which leads to an increase in infarct size and consequent life-threatening arrhythmias [1]. Therefore, myocardial I/R becomes a major limitation of some clinical interventional therapies for coronary artery disease. 
The mechanism underlying cardiac $I / R$ injury remains unclear, but it is reported that $I / R$ significantly increases the production of reactive oxygen species (ROS) generated from complexes I and III of the electron transport chain (ETC) in mitochondria [2]. In addition, treatment with antioxidants such as superoxide dismutase (SOD), catalase (CAT) [3], and antioxidation inducer [4] resulted in the reduction of myocardial I/ $R$ damage. This indicates that natural potent antioxidant characteristics could be beneficial for limiting myocardial I/R injury in IHD patients by scavenging ROS.

Lycopene is a lipophilic natural compound, and has been well studied due to its strong antioxidant properties [5]. It is now known that lycopene is a carotenoid with an open-polyene chain structure similar to $\beta$-carotene but lacking a $\beta$-ionone ring (Figure 1 ). It was originally isolated from black bryony, but commonly enriched from fruits and vegetables such as tomato, pepper, and papaya [6]; thus, lycopene can be easily uptaken from food resources. There are numerous health benefits associated with consuming lycopene. For example, lycopene has been shown to impede prostate cancer progression in patients with benign prostate hyperplasia [7] and protecting against amyloid $\beta$-induced neurotoxicity [8]. In addition, food supplementation of lycopene significantly decreases low-density lipoprotein (LDL) cholesterol serum levels [9] while inhibiting proinflammatory cytokine secretion in obese females [10]. Lycopene deficiency is associated with several chronic diseases including cancer [11], pancreatitis [12], gastritis [13] and atherosclerosis [14]. Notably, there is increasing evidence suggests that low levels of circulating lycopene is associated with increased risk of heart diseases [14,15].

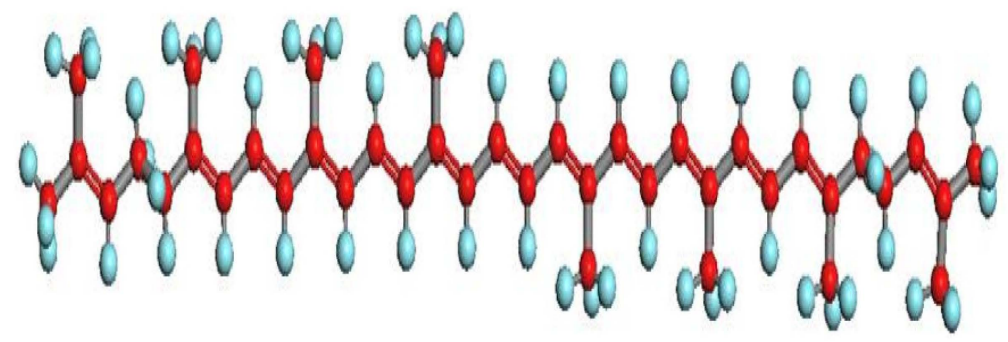

Figure 1. Structure of lycopene.

Epidemiological studies in Europe suggested that higher lycopene concentrations in adipose tissue protect against myocardial infarction (MI) [16], while other groups have shown that prolonged exposure to lycopene attenuated myocardial I/R injury in rat model $[17,18]$. However, both human and animal studies have demonstrated that lycopene is easily absorbed by the body, but predominantly deposited into liver, adrenal, lungs, prostate glands and skin after processing [19,20]. This distribution pattern of lycopene may significantly compromise its benefits for heart diseases [21]; therefore, debate still remains that oral administration of lycopene is efficient enough to protect against myocardial $\mathrm{I} / \mathrm{R}$ injury.

In the present study, we aimed to examine whether intravenous (IV) lycopene administration is beneficial for cardiac I/R injury, and further explore the mechanisms underlying lycopene's effects on myocardial I/R. We attempt to provide evidence that lycopene can be acutely used to treat ischemic heart diseases.

\section{Methods and Materials}

\subsection{Animals, Cell Lines and Chemicals}

Male 10-12 weeks old C57BL/6 mice were animals were obtained from the Experimental Animal Center of Chongqing Medical University. Mice were maintained on a 12-h light-dark cycle in a controlled environment with water ad libitum. All animal experiments were performed in accordance with National Institute of Health (NIH) Guide for the Care and Use of Laboratory Animals. The animal experiments were approved by the Medical Ethics Committee of Chongqing Medical University. HL-1 
cardiomyocytes were generously provided by Claycomb, and cultured as described previously [22]. Lycopene from tomato was purchased from Sigma (St. Louis, MO, USA).

\subsection{In Vitro Hypoxia Model and Trypan Blue Exclusion Assay}

HL-1 cells were seeded in a 12-well plate one day prior to conducting experiments. On the day of experiment, cells were at least $80 \%$ confluent and fresh supplemented Claycomb medium was applied. For hypoxia treatment groups, cells were placed in $95 \%$ nitrogen and $5 \%$ carbon dioxide in a mixed-gas perfusion hypoxia chamber. Cells were allowed to incubate for $2 \mathrm{~h}$ in hypoxic conditions after which solutions of varies lycopene concentrations were added and placed in reoxygenating conditions at $37^{\circ} \mathrm{C}$. Control groups were incubated in normoxia conditions at $37^{\circ} \mathrm{C}$ in a cell culture incubator for $2 \mathrm{~h}$ followed by another $2 \mathrm{~h}$ incubation with vehicle in normoxia. All groups were trypsinized and resuspended in $1.5 \mathrm{~mL}$ HBSS buffer, and then 1:1 diluted with $0.4 \%$ trypan blue solution. After $10 \mathrm{~min}$ of incubation at $37^{\circ} \mathrm{C}$, cells were transferred onto a hemocytometer and counted under a microscope.

\subsection{In Vivo Myocardial I/R Model}

Mice were anaesthetized by sodium pentobarbital $(50 \mathrm{mg} / \mathrm{kg}$ body weight) then placed on a ventilator (Harvard Rodent Ventilator, Harvard) [23]. The body temperature was maintained at $37{ }^{\circ} \mathrm{C}$ with a heating pad. After left lateral thoracotomy, the LAD was occluded for 20 min with an 8-0 nylon suture with a piece of gauze placed between suture and heart to prevent arterial injury. To achieve a $1 \mu \mathrm{M}$ final lycopene concentration in blood plasma, $4 \mu \mathrm{L}$ of $15.6 \mu \mathrm{M}$ lycopene in $0.1 \%$ DMSO or $4 \mu \mathrm{L}$ of $0.1 \%$ DMSO per gram body weight were administered via tail vein injection immediately following 20 min of LAD ligation. ECGs were monitored to confirm the ischemic hallmark of ST-segment elevation during coronary occlusion (ADInstruments, Colorado Springs, CO, USA). Immediately following reperfusion, the left ventricle was separated before freeze clamp in liquid nitrogen and stored in $-80^{\circ} \mathrm{C}$ for further use.

\subsection{Measurement of Myocardial Infarct}

Infarct size was measured as previously described [24]. In short, hearts were reperfused for $4 \mathrm{~h}$ then dual stained. Non-necrosis tissue in the ischemic region was stained red by TTC $(1 \%, w / v)$ and the non-ischemic region was stained blue with Evan's blue $(1 \%, w / v)$. Hearts were fixed in $4 \%$ formalin overnight at $4{ }^{\circ} \mathrm{C}$ and then sectioned into $1 \mathrm{~mm}$ slices in a matrix, photographed using a Leica microscope and analyzed by the use of Image J 1.49 software for Mac OS X (available at http://rsb.info.nih.gov/ij/). The myocardial infarct size was calculated as the extent of myocardial necrosis to the percentage of ischemic area at risk (AAR).

\subsection{MDA Assay}

Cardiac tissue malondialdehyde (MDA) contents were measured using a Lipid Peroxidation (MDA) Assay Kit (Abcam, Cambridge, UK) according to manufacturer's instruction. Briefly, after $20 \mathrm{~min}$ of LAD ligation followed by $20 \mathrm{~min}$ of reperfusion, left ventricles were immediately freeze clamped in liquid nitrogen then stored in an $-80^{\circ} \mathrm{C}$ freezer. $10 \mathrm{mg}$ of each tissue sample was homogenized on ice in $300 \mu \mathrm{L}$ of MDA lysis buffer (with $3 \mu \mathrm{L}$ 100X BHT) then centrifuged at 13,000 g for $10 \mathrm{~min}$. Two hundred microliters of supernatant from each sample was collected and combined with $600 \mu \mathrm{L}$ of TBA solution. Then, $2 \mathrm{mM}$ MDA stock solution was diluted in $\mathrm{ddH}_{2} \mathrm{O}$ to generate $200 \mu \mathrm{L}, 4,8,12,16$ and $20 \mathrm{nmol}$ standards, which were then developed with $600 \mu \mathrm{L}$ of TBA solution. The development of samples and standards was incubated at $95^{\circ} \mathrm{C}$ for $60 \mathrm{~min}$ and then allowed to cool on ice for $10 \mathrm{~min}$. Technical replicates of each sample consisted of $200 \mu \mathrm{L}$ of each and absorbance was measured at $532 \mathrm{~nm}$. 


\subsection{Immunoblotting Analysis}

Western blots were performed as previously described $[25,26]$. In brief, heart tissue samples were homogenized in ice-cold lysis buffer and protein concentration was determined using the Bradford method (Bio-Rad Laboratories, Hercules, CA, USA). Heart homogenate proteins were then resolved by SDS-PAGE and transferred onto polyvinylidene difluoride (PVDF) membranes. For reprobing, membranes were stripped with Restore Western Blot Stripping Buffer from Thermo Scientific (Rockford, IL, USA). Rabbit polyclonal antibodies against AMPK, phosphor-AMPK $\left(\operatorname{Thr}^{172}\right)$, ACC, phosphor-ACC $\left(\mathrm{Ser}^{79}\right)$, p44/42 MAPK, phosphor-p44/42 MAPK (Thr $\left.{ }^{202} / \mathrm{Tyr}^{204}\right)$, p38 MAPK, phosphor-p38 MAPK $\left(\mathrm{Thr}^{180} / \mathrm{Tyr}^{182}\right)$, SAPK/JNK, phosphor-SAPK/JNK $\left(\mathrm{Thr}^{183} / \mathrm{Tyr}^{185}\right)$ and horseradish peroxidase-linked secondary antibody were purchased from Cell Signaling (Danvers, MA, USA).

\subsection{Statistical Analysis}

Data are expressed as mean \pm SEM, and significance is tested by Student's unpaired two-tail $t$ tests or two-way repeated measures ANOVA with Bonferroni correction with $p<0.05$ considered significant.

\section{Results}

\subsection{Lycopene Protects against I/R Induced Cardiomyocyte Death}

To determine whether lycopene is effective in protecting cardiomyocytes against I/R induced cell death and the appropriate dosage for in vivo experiments, we tested the viability of HL-1 cardiomyocytes in an in vitro H/R model by exposing cells to $2 \mathrm{~h}$ of hypoxia followed by $2 \mathrm{~h}$ of reoxygenation as well as varying concentrations of lycopene. Results show that hypoxia/reoxygenation $(\mathrm{H} / \mathrm{R})$ alone significantly reduced cell viability when compared to control $(69.14 \% \pm 0.79 \%$ vs. $94.18 \% \pm 0.50 \%, p<0.001$ ) (Figure 2). Cells treated with $0.5 \mu \mathrm{M}$ lycopene did not attenuate cell death $(69.00 \% \pm 0.98 \%)$. However, higher dosages of lycopene $(1 \mu \mathrm{M}, 2 \mu \mathrm{M}$ and $4 \mu \mathrm{M})$ resulted in $75.16 \% \pm 0.76 \%, 74.97 \% \pm 2.36 \%$, and $75.13 \% \pm 1.05 \%$ cell viability, respectively, demonstrating a significant improvement of cell survival compared to the vehicle group. However, dosages over $1 \mu \mathrm{M}$ failed to achieve higher cell viability than $1 \mu \mathrm{M}$ lycopene treatment. These data suggest that lycopene is protective against $\mathrm{H} / \mathrm{R}$ induced cardiomyocyte death in vitro.

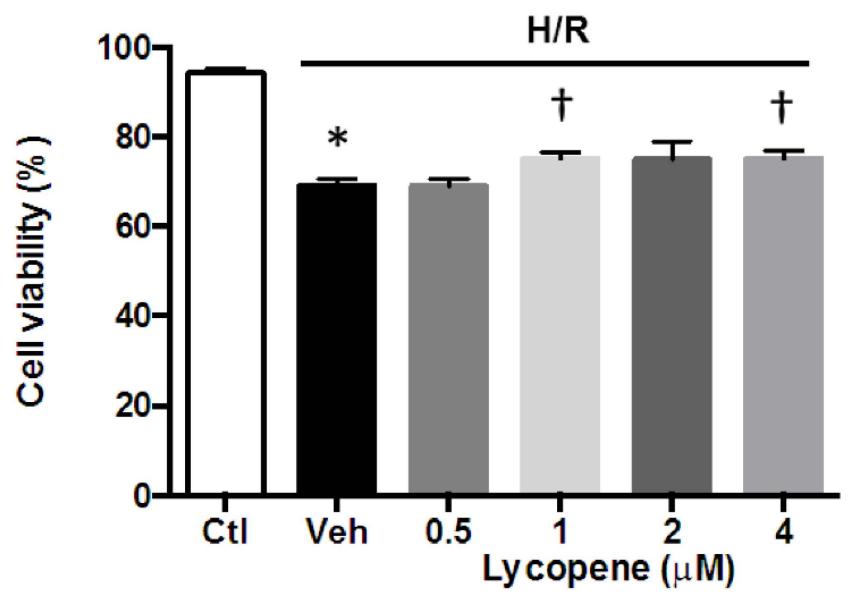

Figure 2. Effect of lycopene on HL-1 cardiomyocytes viability during in vitro hypoxia/reoxygenation (H/R). HL-1 cells were subjected to $2 \mathrm{~h}$ of hypoxia, then treated with $0.5,1,2,4 \mu \mathrm{M}$ lycopene or vehicle alone during $2 \mathrm{~h}$ of reoxygenation. Controls were exposed normaxia throughout the experiment. Cell viability was assessed by trypan blue exclusion. Values are means \pm SEM from three independent experiments, ${ }^{*} p<0.01$ vs. Ctl, $+p<0.01$ vs. Veh. 


\subsection{Effects of Intravenous Administration of Lycopene on I/R Induced Myocardial Infarct}

To confirm the cardioprotective effects of lycopene observed in the in vitro $\mathrm{H} / \mathrm{R}$ cell model, we next examined whether acute lycopene treatment was able to attenuate myocardial infarction in response to in vivo regional I/R. After $20 \mathrm{~min}$ of left descending coronary artery ligation [27], lycopene was administered to animals through tail vein injection followed by $4 \mathrm{~h}$ of reperfusion (Figure 3A). Lycopene administration remarkably decreased the myocardial infarct size compare to the vehicle group $(6.89 \% \pm 0.99 \%$ of AAR vs. $17.06 \% \pm 1.12 \%$ of AAR, $n \geqslant 4$ in each group, $p<0.01$ ) (Figure 3B,C). While there is no difference in AAR to myocardium ratio between lycopene treatment and vehicle group $(69.42 \% \pm 0.92 \%$ vs. $68.21 \% \pm 3.71 \%$ ) (Figure 3D). These data strongly suggest that acute intravenous administration of lycopene ameliorates I/R-induced myocardial injury in mice.

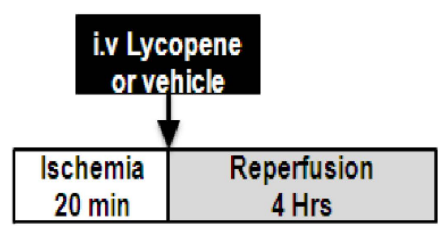

B
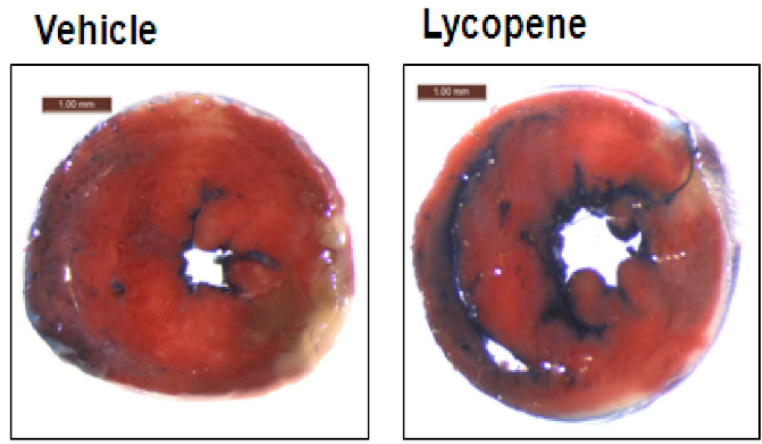

$\mathrm{C}$
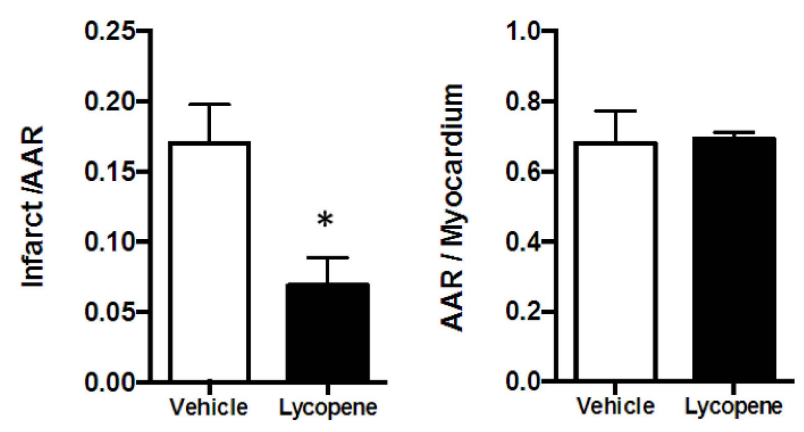

Figure 3. Lycopene (Lyc) reduces myocardial infarct size after ischemia-reperfusion (I/R). In vivo hearts were subjected to $20 \mathrm{~min}$ of ischemia followed by $4 \mathrm{~h}$ of reperfusion. Four microliters of $15.6 \mu \mathrm{M}$ lycopene (in $0.1 \%$ DMSO saline solution, $v / v$ ) or vehicle per gram bodyweight was administrated via tail vein injection after $20 \mathrm{~min}$ of LAD ligation. The extent of myocardial necrosis was assessed by TTC staining. (A) A scheme showing experiment design; (B) representative sections of the extent of myocardial infarction; and (C) ratio of the infarct size to the area at risk (AAR) (left) and the ratio of AAR to the total myocardial area (right). Values are means \pm SEM of $\geqslant 4$ in each group, ${ }^{*} p<0.01$ vs. vehicle.

\subsection{Effect of Lycopene on ROS Generation during $I / R$}

To ascertain whether lycopene reduces MI during I/R by scavenging ROS, we then measured malondialdehyde (MDA) levels in cardiac tissue of the in vivo I/R model. Lycopene or vehicle was given through tail vein injection following $20 \mathrm{~min}$ of ischemia. After $20 \mathrm{~min}$ of reperfusion, cardiac tissue was collected for MDA assay. The data shows that, after $20 \mathrm{~min}$ of ischemia followed by $20 \mathrm{~min}$ of reperfusion, MDA level in vehicle group is $12.70 \pm 1.30 \mathrm{nmol} / \mathrm{g}$ tissue, which has no difference with 
the control group $(13.41 \pm 1.80 \mathrm{nmol} / \mathrm{g}$ ) (Figure 4). However, the lycopene treatment group exhibited a significant reduction in MDA production $(7.54 \pm 1.02 \mathrm{nmol} / \mathrm{g})$ compared to both control and vehicle groups $(n \geqslant 3$ in each group, $p<0.05)$, showing that lycopene reduced ROS generation during acute myocardial I/R. These results indicate the cardioprotective effect against infarction of lycopene may associate with its antioxidant properties.

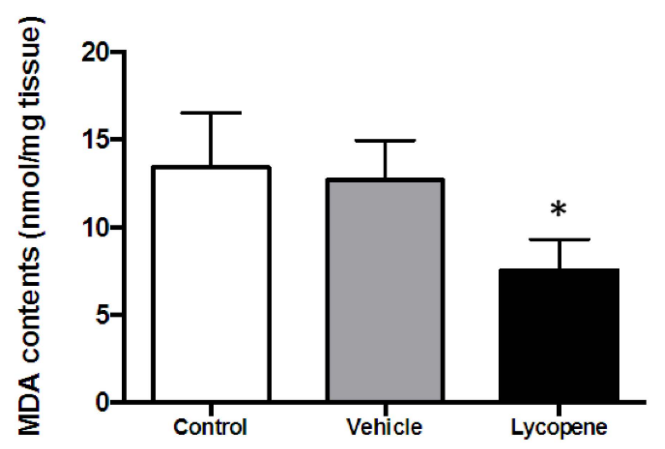

Figure 4. Malondialdehyde (MDA) levels of in vivo I/R cardiac tissue. Lycopene or vehicle was given to mice through tail vein injection after $20 \mathrm{~min}$ of in vivo regional ischemia, then followed by 20 min of reperfusion (I/R); control was not treated with vehicle or lycopene. LVs were harvested immediately after reperfusion then subjected to MDA assay. Values are means \pm SEM, $n \geqslant 3$ in each group, ${ }^{*} p<0.05$ vs. control and vehicle.

\subsection{Signaling Pathways Regulated by Acute Lycopene Treatment during I/R}

Fatty acid $\beta$-oxidation is the major source of ROS generation during myocardial I/R. To further determine whether reduced MDA production by lycopene is derived from suppressing fatty acid $\beta$-oxidation, we measured a key regulator of fatty acid metabolism, AMP activated kinase (AMPK), and its direct downstream effector, acetyl-CoA carboxylase (ACC) [28], a rate-limiting enzyme for fatty acid $\beta$-oxidation in our in vivo myocardial I/R mouse model. Western blotting data illustrated that 20 min of ischemia resulted in a significant increase in AMPK phosphorylation (Figure 5A) while 20 min of reperfusion reduced AMPK phosphorylation levels similar to those at baseline. We also observed a moderate upregulation of AMPK following lycopene treatment (Figure 5A). Phosphorylation of ACC was significantly elevated by ischemic stress followed by dephosphorylation during reperfusion. However, in the presence of lycopene, ACC remained phosphorylated during reperfusion (Figure 5B). This suggests that lycopene does not inhibit fatty acid oxidation during myocardial I/ $R$ rather it moderately activates the AMPK-ACC signaling pathway. Therefore, the reduction of cardiac MDA level during I/R by lycopene administration may be a direct result of its antioxidative properties.

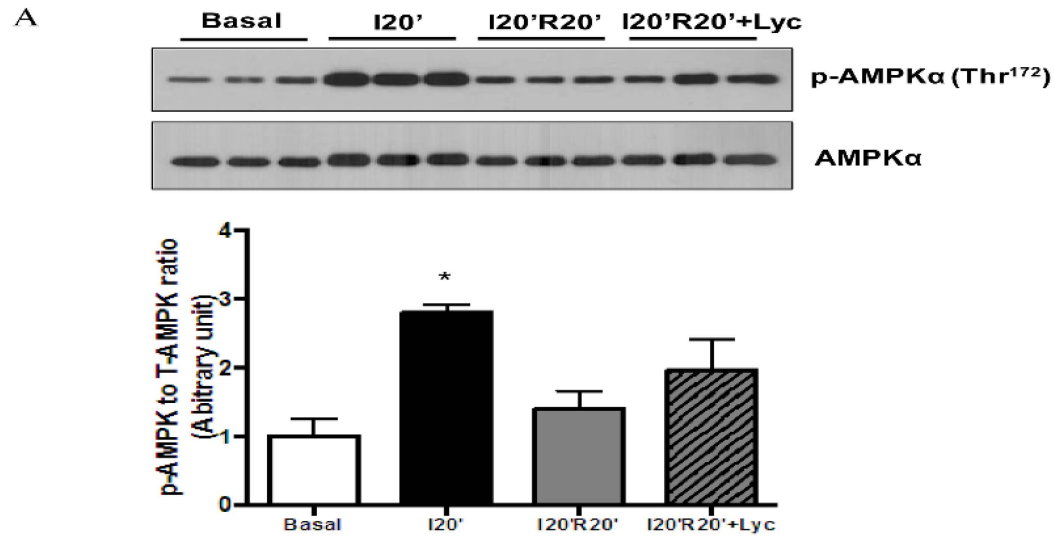

Figure 5. Cont. 
B

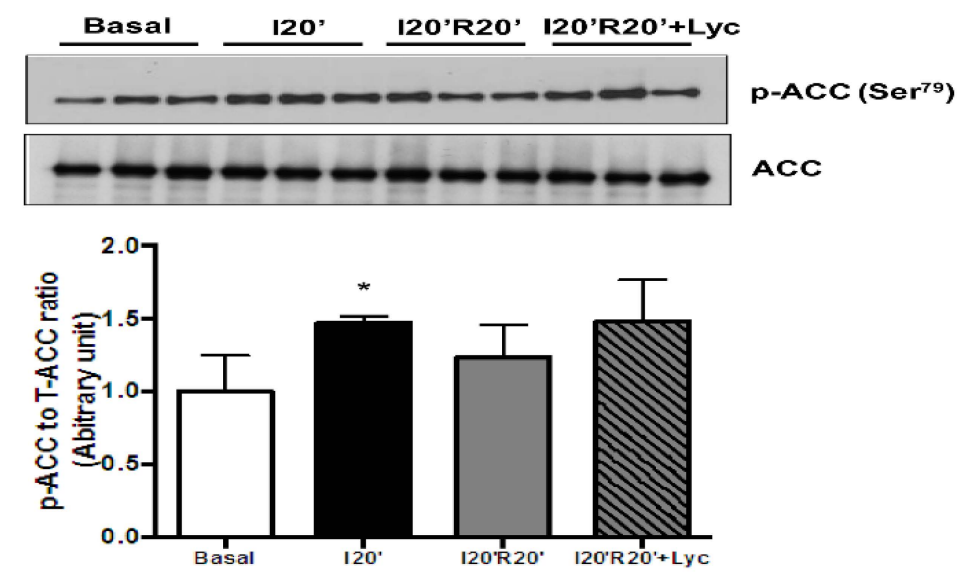

Figure 5. Effects of lycopene (Lyc) on fatty acid oxidation regulating signaling during in vivo I/R: (A) lycopene treatment moderately elevated AMPK phosphorylation at $\mathrm{Thr}^{172}$ during reperfusion, ${ }^{*} p<0.01$ vs. basal; and (B) lycopene mildly augmented ACC phosphorylation at Ser ${ }^{79}$ during reperfusion, ${ }^{*} p<0.01$ vs. basal. Values are means \pm SEM, $n \geqslant 3$ in each group.

Mitogen-activated protein kinases (MAPK) are a protein family of serine-threonine kinases that play a critical role in numerous cellular processes in response to environmental stress as well as regulating inflammation [29]. To further explore whether lycopene has an impact on modulating MAPK signaling pathways and inflammation during $I / R$, we then examined the total expression levels and phosphorylation levels of JNK, p44/42 MAPK and p38 MAPK in cardiac tissue from the in vivo I/R model. Results showed that phosphor-JNK ( $\mathrm{Thr}^{183} / \mathrm{Tyr}^{185}$ ) was dramatically elevated by $I / R$, but significantly downregulated by lycopene treatment, in the absence of change in total protein (Figure 6A). Similarly, phosphor-p44/42 MAPK $\left(\mathrm{Thr}^{202} / \mathrm{Tyr}^{204}\right.$ ) to total p44/42 MAPK ratio revealed a trend of reduction by lycopene administration compared to vehicle treatment during reperfusion (Figure 6B), while we did not observe significant effects of acute lycopene treatment on p38 MAPK phosphorylation in our study due to large variation in experimental groups (Figure 6C). Taken together, acute lycopene administration via IV injection ameliorates inflammation by attenuating the JNK signaling pathway during I/R.

A
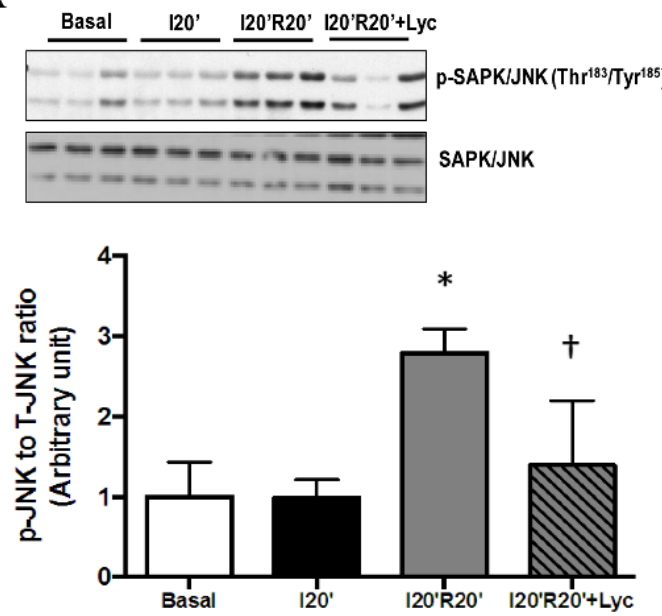

B
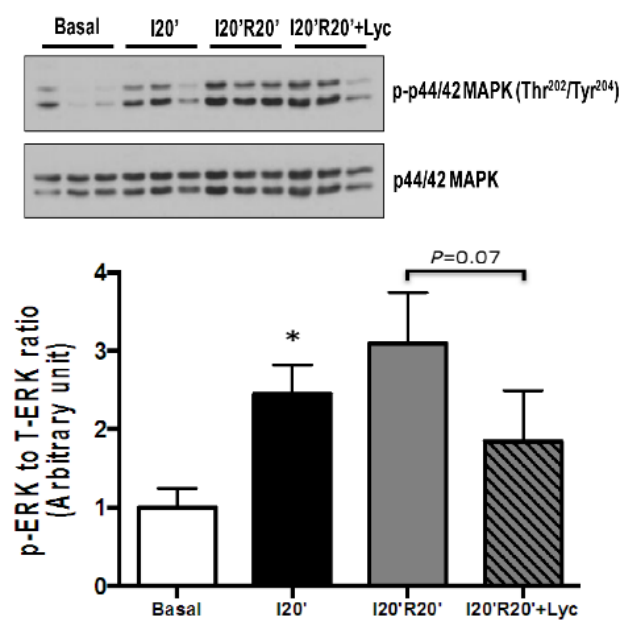

Figure 6. Cont. 


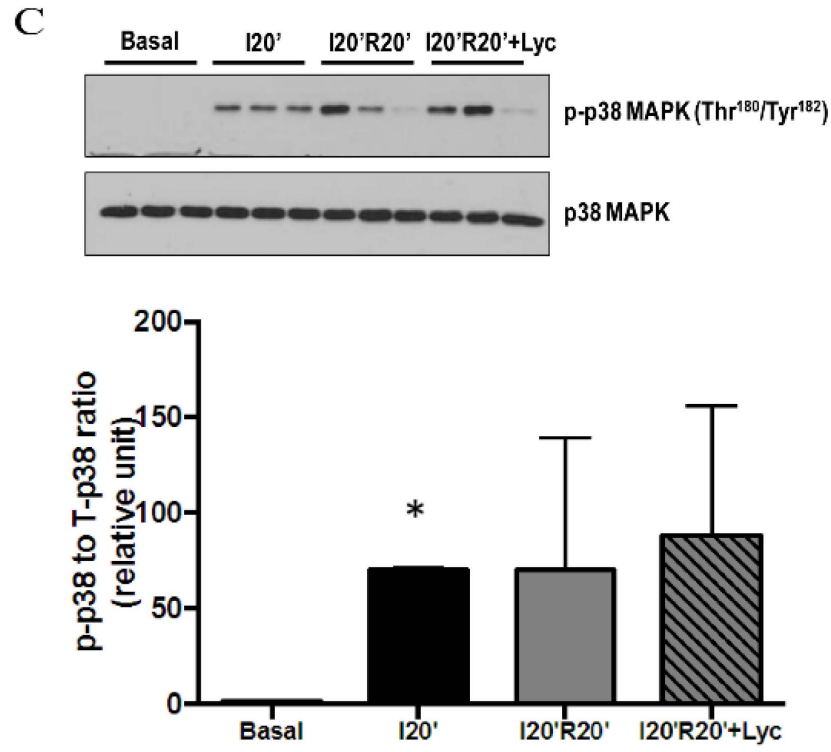

Figure 6. Effects of acute lycopene (Lyc) administration on MAPK signaling pathways during in vivo I/R: (A) lycopene administration significantly attenuated JNK phosphorylation at $\mathrm{Thr}^{183} / \mathrm{Tyr}^{185}$ during reperfusion, ${ }^{*} p<0.01$ vs. basal and I20',$+ p<0.05$ vs. I20'R20' vehicle; (B) lycopene reduced $\mathrm{p} 42 / 44$ phosphorylation at $\mathrm{Thr}^{202} / \mathrm{Tyr}^{204}$ during reperfusion, ${ }^{*} p<0.01$ vs. basal, $p=0.07$ vs. I20'R20' vehicle; and (C) lycopene has no impact on p38 phosphorylation during reperfusion, ${ }^{*} p<0.01$ vs. basal. Values are means \pm SEM, $n \geqslant 3$ in each group.

\section{Discussion}

Lycopene has been shown to be beneficial for I/R injury in a variety of organs including brain [30], testicle [31], and heart [17,18], suggesting it could be clinically utilized for IHD management. However, the in vivo distribution pattern of lycopene determined by the use of isotope and mass spectrometry demonstrated that it is predominantly deposited to liver after digestion $[19,20]$. Moreover, it has been reported that no further increases in serum or tissue concentrations in rats fed with dietary lycopene over $0.5 \mathrm{~g} / \mathrm{kg} /$ day [32], suggesting there is a strong first-pass metabolism for lycopene and thereby the relatively low bioavailability restricts the therapeutic application of lycopene through oral intake. Thus, the effectiveness of oral uptake of lycopene for treating ischemic diseases has been questioned. On the contrary, intravenous administration can rapidly and significantly increase circulating lycopene levels and could be more efficient at protecting against myocardiac I/R injury.

In the present study, we firstly examined whether acute lycopene administration is able to prevent $\mathrm{I} / \mathrm{R}$ induced cardiomyocyte death. Our data indicates that acute treatment of $1 \mu \mathrm{M}$ lycopene is effective to improve cardiomyocyte viability during in vitro $\mathrm{H} / \mathrm{R}$, which is consistent with previous findings from $\mathrm{H} 9 \mathrm{C} 2$ fibroblasts [33]. These findings suggest that extracellular lycopene concentration may be critical for preventing ROS induced cell death during I/R. In addition, we also determined that lycopene concentrations higher than $1 \mu \mathrm{M}$ did not further improve cell viability, which is consistent with recent report from Gao et al., which demonstrated that $1.25 \mu \mathrm{M}$ lycopene treatment significantly elevated the survival rate of $\mathrm{H} 9 \mathrm{C} 2$ cells during $\mathrm{H} / \mathrm{R}$, while increase the dosage to $20 \mu \mathrm{M}$ did not achieve further improvement [34].

Yue et al. have shown that lycopene-fed rats have smaller infarct size after cardiac I/R [35], to investigate whether IV administration of lycopene could also protect against I/R induced MI, we then established an in vivo myocardial I/R mouse model. Since our cell experiments have demonstrated $1 \mu \mathrm{M}$ lycopene is effective to suppress $\mathrm{H} / \mathrm{R}$ induced cardiomyocyte death, and Schierle et al. reported that lycopene concentrations in human blood plasma range from 0.2 to $1 \mu \mathrm{M}$ [28], we sought to determine whether $1 \mu \mathrm{M}$ of lycopene prevents I/ $\mathrm{R}$ induced MI in vivo. To achieve a $1 \mu \mathrm{M}$ lycopene 
in blood circulation, $4 \mu \mathrm{L}$ of $15.6 \mu \mathrm{M}$ lycopene in $0.1 \%$ DMSO per gram body weight given to mice through tail vein injection immediately before reperfusion. TTC dual staining results suggest that $1 \mu \mathrm{M}$ lycopene is sufficient to attenuated I/ $\mathrm{R}$ induced $\mathrm{MI}$ in mice. To the best of our knowledge, we are the first group to report that IV lycopene administration alleviates I/R induced MI, and our evidence strongly suggests that IV lycopene administration could be a potential therapeutic approach for I/R injury management.

It is known that myocardial ischemia breaks the homeostasis between energetic substrate delivery within the blood stream and the metabolic requirements of the heart [36]. Hence, during ischemia, the activity of mitochondria is inhibited due to oxygen shortages [37], which in turn leads to cardiomyocytes undergoing nutrient deprivation and stress. As a consequence, reperfusion after a short ischemic episode promotes oxidative phosphorylation to compensate for the energy loss. Meanwhile, ROS is dramatically generated from ETC [2], which will further impair mitochondrial respiratory function [38], exacerbate cardiomyocyte contractile malfunction and cause other symptoms of cardiomyopathy [39]. It has been reported that lycopene attenuates $\mathrm{H}_{2} \mathrm{O}_{2}$ induced apoptosis in H9C2 cell [35], which implies the cardioprotective effect of lycopene is associated with ROS scavenging. To study whether IV lycopene administration protects against cardiac I/R injury by reducing ROS generation during reperfusion, we next measured MDA levels in our in vivo myocardial I/R model. Our results demonstrate that acute lycopene administration effectively reduced MDA production during reperfusion indicating that cardiac ROS accumulation during I/R is suppressed by lycopene treatment. This finding is consistent with multiple reports that show lycopene decreases ROS levels in varies models [35,40]. Although previous studies also suggest that lycopene upregulates antioxidant response elements and nuclear factor E2-related factor 2 [41], increases of antioxidant enzymes expression including SOD, CAT, the metal binding protein transferrin, and epoxide hydrolase 1 [42], the effect of lycopene on antioxidants expression may not be the primary protective mechanism in the setting of short-time I/R induced myocardial injury.

To further distinguish whether the cardioprotective effects of lycopene are derived from its direct antioxidative properties or its effects on modulating fatty acid oxidation, we next analyzed the AMPK-ACC signaling pathway in the in vivo I/R model. Our data show that acute lycopene moderately promoted AMPK-ACC signaling pathway activation during reperfusion. Although the observed changes were not statistically significant, it indicates that capturing ROS rather than inhibiting fatty acid utilization contributes to lower ROS accumulation during I/R by acute lycopene administration. Interestingly, it is known that AMPK exhibits cardioprotective effects during I/R injury by promoting GLUT4 mediated glucose uptake [43]. Santulli et al. have reported that abnormal $\mathrm{Ca}^{2+}$ release from sarcoplasmic reticulum is a key step for postischemic heart failure [44], giving that calmodulin-dependent kinase kinase beta $(\mathrm{CaMKK} \beta)$ is an upstream regulator of AMPK [45], it will be interesting to investigate whether lycopene could regulate $\mathrm{Ca}^{2+}$ signal and mitochondrial function in cardiomyocyte during I/R. Moreover, to further explore the correlation between lycopene and AMPK during cardiac I/R, the use of an AMPK knockout animal model will be very helpful to better understand the mechanism of lycopene in attenuating I/R induced MI.

Previous studies have demonstrated that MAPK can be activated by stress and inflammatory stimuli [29] while several studies have documented that myocardial I/R is associated with MAPK activation [46,47], and pharmacological inhibition of JNK is beneficial for limiting I/R injury [48,49] We report that along with reduced myocardial infarct size, acute lycopene administration also significantly inhibited JNK phosphorylation at $\mathrm{Thr}^{183} / \mathrm{Tyr}^{185}$ during reperfusion, which is consistent with previous findings that lycopene treatment inhibits $\mathrm{H}_{2} \mathrm{O}_{2}$ induced JNK phosphorylation [50]. Furthermore, we report that lycopene treatment lowers p44/42 MAPK phosphorylation during reperfusion compare to vehicle. Previous studies have shown that p44/42 MAPK phosphorylation during $\mathrm{I} / \mathrm{R}$ is cardioprotective $[47,51]$. However, in these studies, pharmacological p44/42 MAPK inhibitors, PD98059 and UO126 were utilized to examine the function of p44/42 MAPK during cardiac $\mathrm{I} / \mathrm{R}$, both of which dramatically inhibited p44/42 MAPK activation and resulted in worsening I/R 
injury. In our study, p44/42 MAPK phosphorylation in lycopene treated groups was found to be lower than vehicle groups during reperfusion but still maintained a notable increase compared to the basal condition. Reduction of p44/42 MAPK phosphorylation by lycopene may result from less ROS stress. Although p38 MAPK activation is also associated with ischemic stress [52,53], we report no difference in $\mathrm{p} 38$ MAPK phosphorylation during $\mathrm{I} / \mathrm{R}$ as a result of lycopene administration.

In summary, lycopene is a natural potent antioxidant and has long been associated with human health. We utilized both in vitro and in vivo I/R models to evaluate the effects of lycopene on cardiomyocyte following I/R injury. In this study, we first report that acute lycopene administration through IV injection protects against I/R induced MI. In addition, our data also elucidated that JNK activation during reperfusion is suppressed by acute lycopene administration, which indicating lycopene ameliorate inflammation during $I / R$ probably due to its effects on scavenging ROS. Nevertheless, other groups have suggested that lycopene reduces myocardial I/R injury by promoting autophage, and alleviating endoplasmic reticulum stress [54,55]. Taken together, these findings indicate that lycopene may prevent myocardial I/R injury through multiple pathways and mechanisms. There are many limitations still remain in this study, such as the dose-response curve of lycopene for in vivo $\mathrm{I} / \mathrm{R}$ is missing, did not provide cardiac troponin I value to assess MI; and failed to perform postischemic cardiac contractile function measurement. In addition, we acknowledge the working concentration of lycopene in our study is too high to be used clinically. Therefore, we feel that further studies on more potent lycopene isomers and/or derivatives need to be conducted due to lycopene's potential therapeutic effects in treating IHD.

\section{Conclusions}

In conclusion, the present study reveals that $1 \mu \mathrm{M}$ lycopene treatment immediately before reoxygenation significantly represses $\mathrm{H} / \mathrm{R}$ induced cardiomyocytes death. Moreover, supplement of $1 \mu \mathrm{M}$ circulating lycopene in blood via IV injection effectively reduced MI during in vivo I/R in mice, and significantly inhibited fatty acid oxidation and JNK signaling activation during reperfusion.

Acknowledgments: This work is supported by the Natural Science Foundation of China (81300678 to CT).

Author Contributions: C.T. and H.Z. conceived and designed the experiments; L.W., C.P., L.Z., X.Y., and T.B. performed the experiments; P.X. and J.L. analyzed the data; H.Z. and H.Q. contributed equipment and laboratory; and T.D. and C.T. wrote the paper.

Conflicts of Interest: The authors declare no conflict of interest.

\section{References}

1. Liu, Y.H.; Yang, X.P.; Sharov, V.G.; Sigmon, D.H.; Sabbah, H.N.; Carretero, O.A. Paracrine systems in the cardioprotective effect of angiotensin-converting enzyme inhibitors on myocardial ischemia reperfusion injury in rats. Hypertension 1996, 27, 7-13. [CrossRef] [PubMed]

2. Chen, Q.; Moghaddas, S.; Hoppel, C.L.; Lesnefsky, E.J. Ischemic defects in the electron transport chain increase the production of reactive oxygen species from isolated rat heart mitochondria. Am. J. Physiol. Cell Physiol. 2008, 294, C460-C466. [CrossRef] [PubMed]

3. Jolly, S.R.; Kane, W.J.; Bailie, M.B.; Abrams, G.D.; Lucchesi, B.R. Canine myocardial reperfusion injury-Its reduction by the combined administration of superoxide-dismutase and catalase. Circ. Res. 1984, 54, $277-285$. [CrossRef] [PubMed]

4. Piao, C.S.; Gao, S.; Lee, G.H.; Kim, D.S.; Park, B.H.; Chae, S.W.; Chae, H.J.; Kim, S.H. Sulforaphane protects ischemic injury of hearts through antioxidant pathway and mitochondrial k-atp channels. Pharmacol. Res. 2010, 61, 342-348. [CrossRef] [PubMed]

5. Di Mascio, P.; Kaiser, S.; Sies, H. Lycopene as the most efficient biological carotenoid singlet oxygen quencher. Arch. Biochem. Biophys. 1989, 274, 532-538. [CrossRef]

6. Khachik, F.; Carvalho, L.; Bernstein, P.S.; Muir, G.J.; Zhao, D.Y.; Katz, N.B. Chemistry, distribution, and metabolism of tomato carotenoids and their impact on human health. Exp. Biol. Med. 2002, 227, 845-851. 
7. Schwarz, S.; Obermuller-Jevic, U.C.; Hellmis, E.; Koch, W.; Jacobi, G.; Biesalski, H.K. Lycopene inhibits disease progression in patients with benign prostate hyperplasia. J. Nutr. 2008, 138, 49-53. [PubMed]

8. Qu, M.; Li, L.; Chen, C.; Li, M.; Pei, L.; Chu, F.; Yang, J.; Yu, Z.; Wang, D.; Zhou, Z. Protective effects of lycopene against amyloid beta-induced neurotoxicity in cultured rat cortical neurons. Neurosci. Lett. 2011, 505, 286-290. [CrossRef] [PubMed]

9. Lorenz, M.; Fechner, M.; Kalkowski, J.; Frohlich, K.; Trautmann, A.; Bohm, V.; Liebisch, G.; Lehneis, S.; Schmitz, G.; Ludwig, A.; et al. Effects of lycopene on the initial state of atherosclerosis in New Zealand white (nzw) rabbits. PLoS ONE 2012, 7, e30808. [CrossRef] [PubMed]

10. Ghavipour, M.; Saedisomeolia, A.; Djalali, M.; Sotoudeh, G.; Eshraghyan, M.R.; Moghadam, A.M.; Wood, L.G. Tomato juice consumption reduces systemic inflammation in overweight and obese females. Br. J. Nutr. 2013, 109, 2031-2035. [CrossRef] [PubMed]

11. Giovannucci, E. Tomatoes, tomato-based products, lycopene, and cancer: Review of the epidemiologic literature. J. Natl. Cancer Inst. 1999, 91, 317-331. [CrossRef] [PubMed]

12. Quilliot, D.; Forbes, A.; Dubois, F.; Gueant, J.L.; Ziegler, O. Carotenoid deficiency in chronic pancreatitis: The effect of an increase in tomato consumption. Eur. J. Clin. Nutr. 2011, 65, 262-268. [CrossRef] [PubMed]

13. Sanderson, M.J.; White, K.L.; Drake, I.M.; Schorah, C.J. Vitamin e and carotenoids in gastric biopsies: The relation to plasma concentrations in patients with and without helicobacter pylori gastritis. Am. J. Clin. Nutr. 1997, 65, 101-106. [PubMed]

14. Rissanen, T.H.; Voutilainen, S.; Nyyssonen, K.; Salonen, R.; Kaplan, G.A.; Salonen, J.T. Serum lycopene concentrations and carotid atherosclerosis: The kuopio ischaemic heart disease risk factor study. Am. J. Clin. Nutr. 2003, 77, 133-138. [PubMed]

15. Sesso, H.D.; Buring, J.E.; Norkus, E.P.; Gaziano, J.M. Plasma lycopene, other carotenoids, and retinol and the risk of cardiovascular disease in women. Am. J. Clin. Nutr. 2004, 79, 47-53. [PubMed]

16. Kohlmeier, L.; Kark, J.D.; Gomez-Gracia, E.; Martin, B.C.; Steck, S.E.; Kardinaal, A.F.; Ringstad, J.; Thamm, M.; Masaev, V.; Riemersma, R.; et al. Lycopene and myocardial infarction risk in the euramic study. Am. J. Epidemiol. 1997, 146, 618-626. [CrossRef] [PubMed]

17. Bansal, P.; Gupta, S.K.; Ojha, S.K.; Nandave, M.; Mittal, R.; Kumari, S.; Arya, D.S. Cardioprotective effect of lycopene in the experimental model of myocardial ischemia-reperfusion injury. Mol. Cell. Biochem. 2006, 289, 1-9. [CrossRef] [PubMed]

18. Aman, U.; Vaibhav, P.; Balaraman, R. Tomato lycopene attenuates myocardial infarction induced by isoproterenol: Electrocardiographic, biochemical and anti-apoptotic study. Asian Pac. J. Trop. Biomed. 2012, 2, 345-351. [PubMed]

19. Ross, A.B.; Vuong le, T.; Ruckle, J.; Synal, H.A.; Schulze-Konig, T.; Wertz, K.; Rumbeli, R.; Liberman, R.G.; Skipper, P.L.; Tannenbaum, S.R.; et al. Lycopene bioavailability and metabolism in humans: An accelerator mass spectrometry study. Am. J. Clin. Nutr. 2011, 93, 1263-1273. [CrossRef] [PubMed]

20. Moran, N.E.; Clinton, S.K.; Erdman, J.W., Jr. Differential bioavailability, clearance, and tissue distribution of the acyclic tomato carotenoids lycopene and phytoene in mongolian gerbils. J. Nutr. 2013, 143, 1920-1926. [CrossRef] [PubMed]

21. Collins, J.K.; Arjmandi, B.H.; Claypool, P.L.; Perkins-Veazie, P.; Baker, R.A.; Clevidence, B.A. Lycopene from two food sources does not affect antioxidant or cholesterol status of middle-aged adults. Nutr. J. 2004, 3. [CrossRef] [PubMed]

22. Claycomb, W.C.; Lanson, N.A., Jr.; Stallworth, B.S.; Egeland, D.B.; Delcarpio, J.B.; Bahinski, A.; Izzo, N.J., Jr. Hl-1 cells: A cardiac muscle cell line that contracts and retains phenotypic characteristics of the adult cardiomyocyte. Proc. Natl. Acad. Sci. USA 1998, 95, 2979-2984. [CrossRef] [PubMed]

23. Miller, E.J.; Li, J.; Leng, L.; McDonald, C.; Atsumi, T.; Bucala, R.; Young, L.H. Macrophage migration inhibitory factor stimulates AMP-activated protein kinase in the ischaemic heart. Nature 2008, 451, U578-U579. [CrossRef] [PubMed]

24. Tong, C.; Morrison, A.; Mattison, S.; Qian, S.; Bryniarski, M.; Rankin, B.; Wang, J.; Thomas, D.P.; Li, J. Impaired sirt1 nucleocytoplasmic shuttling in the senescent heart during ischemic stress. FASEB J. 2013, 27, 4332-4342. [CrossRef] [PubMed]

25. Ma, H.; Wang, J.; Thomas, D.P.; Tong, C.; Leng, L.; Wang, W.; Merk, M.; Zierow, S.; Bernhagen, J.; Ren, J.; et al. Impaired macrophage migration inhibitory factor-AMP-activated protein kinase activation and ischemic recovery in the senescent heart. Circulation 2010, 122, 282-292. [CrossRef] [PubMed] 
26. Wang, J.; Ma, H.; Tong, C.; Zhang, H.; Lawlis, G.B.; Li, Y.; Zang, M.; Ren, J.; Nijland, M.J.; Ford, S.P.; et al. Overnutrition and maternal obesity in sheep pregnancy alter the JNK-IRS-1 signaling cascades and cardiac function in the fetal heart. FASEB J. 2010, 24, 2066-2076. [CrossRef] [PubMed]

27. Hladunewich, M.; Karumanchi, S.A.; Lafayette, R. Pathophysiology of the clinical manifestations of preeclampsia. Clin. J. Am. Soc. Nephrol. CJASN 2007, 2, 543-549. [CrossRef] [PubMed]

28. Schierle, J.; Bretzel, W.; Buhler, I.; Faccin, N.; Hess, D.; Steiner, K.; Schuep, W. Content and isomeric ratio of lycopene in food and human blood plasma. Food Chem. 1997, 59, 459-465. [CrossRef]

29. Kyriakis, J.M.; Avruch, J. Mammalian mapk signal transduction pathways activated by stress and inflammation: A 10-year update. Physiol. Rev. 2012, 92, 689-737. [CrossRef] [PubMed]

30. Fujita, K.; Yoshimoto, N.; Kato, T.; Imada, H.; Matsumoto, G.; Inakuma, T.; Nagata, Y.; Miyachi, E. Lycopene inhibits ischemia/reperfusion-induced neuronal apoptosis in gerbil hippocampal tissue. Neurochem. Res. 2013, 38, 461-469. [CrossRef] [PubMed]

31. Hekimoglu, A.; Kurcer, Z.; Aral, F.; Baba, F.; Sahna, E.; Atessahin, A. Lycopene, an antioxidant carotenoid, attenuates testicular injury caused by ischemia/reperfusion in rats. Tohoku J. Exp. Med. 2009, 218, 141-147. [CrossRef] [PubMed]

32. Boileau, T.W.; Clinton, S.K.; Erdman, J.W., Jr. Tissue lycopene concentrations and isomer patterns are affected by androgen status and dietary lycopene concentration in male f344 rats. J. Nutr. 2000, 130, 1613-1618. [PubMed]

33. Li, H.; Deng, Z.; Liu, R.; Loewen, S.; Tsao, R. Carotenoid compositions of coloured tomato cultivars and contribution to antioxidant activities and protection against $\mathrm{H}_{2} \mathrm{O}_{2}$-induced cell death in $\mathrm{H} 9 \mathrm{C} 2$. Food Chem. 2013, 136, 878-888. [CrossRef] [PubMed]

34. Gao, Y.; Jia, P.; Shu, W.; Jia, D. The protective effect of lycopene on hypoxia/reoxygenation-induced endoplasmic reticulum stress in H9C2 cardiomyocytes. Eur. J. Pharmacol. 2016. [CrossRef] [PubMed]

35. Yue, R.; Hu, H.; Yiu, K.H.; Luo, T.; Zhou, Z.; Xu, L.; Zhang, S.; Li, K.; Yu, Z. Lycopene protects against hypoxia/reoxygenation-induced apoptosis by preventing mitochondrial dysfunction in primary neonatal mouse cardiomyocytes. PLOS ONE 2012, 7, e50778.

36. Rosano, G.M.C.; Fini, M.; Caminiti, G.; Barbaro, G. Cardiac metabolism in myocardial ischemia. Curr. Pharm. Des. 2008, 14, 2551-2562. [CrossRef] [PubMed]

37. Zhou, L.F.; Salem, J.E.; Saidel, G.M.; Stanley, W.C.; Cabrera, M.E. Mechanistic model of cardiac energy metabolism predicts localization of glycolysis to cytosolic subdomain during ischemia. Am. J. Physiol. Heart C 2005, 288, H2400-H2411. [CrossRef] [PubMed]

38. Paradies, G.; Petrosillo, G.; Pistolese, M.; Di Venosa, N.; Federici, A.; Ruggiero, F.M. Decrease in mitochondrial complex I activity in ischemic/reperfused rat heart-Involvement of reactive oxygen species and cardiolipin. Circ. Res. 2004, 94, 53-59. [CrossRef] [PubMed]

39. Ye, G.; Metreveli, N.S.; Donthi, R.V.; Xia, S.; Xu, M.; Carlson, E.C.; Epstein, P.N. Catalase protects cardiomyocyte function in models of type 1 and type 2 diabetes. Diabetes 2004, 53, 1336-1343. [CrossRef] [PubMed]

40. Krishnamoorthy, G.; Selvakumar, K.; Venkataraman, P.; Elumalai, P.; Arunakaran, J. Lycopene supplementation prevents reactive oxygen species mediated apoptosis in sertoli cells of adult albino rats exposed to polychlorinated biphenyls. Interdiscip. Toxicol. 2013, 6, 83-92. [CrossRef] [PubMed]

41. Ben-Dor, A.; Steiner, M.; Gheber, L.; Danilenko, M.; Dubi, N.; Linnewiel, K.; Zick, A.; Sharoni, Y.; Levy, J. Carotenoids activate the antioxidant response element transcription system. Mol. Cancer Ther. 2005, 4, 177-186. [PubMed]

42. Goo, Y.A.; Li, Z.; Pajkovic, N.; Shaffer, S.; Taylor, G.; Chen, J.; Campbell, D.; Arnstein, L.; Goodlett, D.R.; van Breemen, R.B. Systematic investigation of lycopene effects in lncap cells by use of novel large-scale proteomic analysis software. Proteom. Clin. Appl. 2007, 1, 513-523. [CrossRef] [PubMed]

43. Russell, R.R., 3rd; Li, J.; Coven, D.L.; Pypaert, M.; Zechner, C.; Palmeri, M.; Giordano, F.J.; Mu, J.; Birnbaum, M.J.; Young, L.H. AMP-activated protein kinase mediates ischemic glucose uptake and prevents postischemic cardiac dysfunction, apoptosis, and injury. J. Clin. Investig. 2004, 114, 495-503. [CrossRef] [PubMed]

44. Santulli, G.; Xie, W.; Reiken, S.R.; Marks, A.R. Mitochondrial calcium overload is a key determinant in heart failure. Proc. Natl. Acad. Sci. USA 2015, 112, 11389-11394. [CrossRef] [PubMed] 
45. Hawley, S.A.; Pan, D.A.; Mustard, K.J.; Ross, L.; Bain, J.; Edelman, A.M.; Frenguelli, B.G.; Hardie, D.G. Calmodulin-dependent protein kinase kinase-beta is an alternative upstream kinase for AMP-activated protein kinase. Cell Metab. 2005, 2, 9-19. [CrossRef] [PubMed]

46. Armstrong, S.C. Protein kinase activation and myocardial ischemia/reperfusion injury. Cardiovasc. Res. 2004, 61, 427-436. [CrossRef] [PubMed]

47. Yue, T.L.; Wang, C.; Gu, J.L.; Ma, X.L.; Kumar, S.; Lee, J.C.; Feuerstein, G.Z.; Thomas, H.; Maleeff, B.; Ohlstein, E.H. Inhibition of extracellular signal-regulated kinase enhances ischemia/reoxygenation-induced apoptosis in cultured cardiac myocytes and exaggerates reperfusion injury in isolated perfused heart. Circ. Res. 2000, 86, 692-699. [CrossRef] [PubMed]

48. Ferrandi, C.; Ballerio, R.; Gaillard, P.; Giachetti, C.; Carboni, S.; Vitte, P.A.; Gotteland, J.P.; Cirillo, R. Inhibition of c-Jun $\mathrm{N}$-terminal kinase decreases cardiomyocyte apoptosis and infarct size after myocardial ischemia and reperfusion in anaesthetized rats. Br. J. Pharmacol. 2004, 142, 953-960. [CrossRef] [PubMed]

49. Qi, D.; Hu, X.; Wu, X.; Merk, M.; Leng, L.; Bucala, R.; Young, L.H. Cardiac macrophage migration inhibitory factor inhibits jnk pathway activation and injury during ischemia/reperfusion. J. Clin. Investig. 2009, 119, 3807-3816. [CrossRef] [PubMed]

50. Kim, J.Y.; Lee, J.S.; Han, Y.S.; Lee, J.H.; Bae, I.; Yoon, Y.M.; Kwon, S.M.; Lee, S.H. Pretreatment with lycopene attenuates oxidative stress-induced apoptosis in human mesenchymal stem cells. Biomol. Ther. 2015, 23, 517-524. [CrossRef] [PubMed]

51. Strohm, C.; Barancik, T.; Bruhl, M.L.; Kilian, S.A.; Schaper, W. Inhibition of the ER-kinase cascade by PD98059 and UO126 counteracts ischemic preconditioning in pig myocardium. J. Cardiovasc. Pharmacol. 2000, 36, 218-229. [CrossRef] [PubMed]

52. Barancik, M.; Htun, P.; Strohm, C.; Kilian, S.; Schaper, W. Inhibition of the cardiac p38-MAPK pathway by SB203580 delays ischemic cell death. J. Cardiovasc. Pharmacol. 2000, 35, 474-483. [CrossRef] [PubMed]

53. Li, J.; Miller, E.J.; Ninomiya-Tsuji, J.; Russell, R.R., 3rd; Young, L.H. AMP-activated protein kinase activates p38 mitogen-activated protein kinase by increasing recruitment of p38 MAPK to tab1 in the ischemic heart. Circ. Res. 2005, 97, 872-879. [CrossRef] [PubMed]

54. Chen, F.; Sun, Z.W.; Ye, L.F.; Fu, G.S.; Mou, Y.; Hu, S.J. Lycopene protects against apoptosis in hypoxia/reoxygenationinduced H9C2 myocardioblast cells through increased autophagy. Mol. Med. Rep. 2015, 11, 1358-1365. [PubMed]

55. Xu, J.; Hu, H.; Chen, B.; Yue, R.; Zhou, Z.; Liu, Y.; Zhang, S.; Xu, L.; Wang, H.; Yu, Z. Lycopene protects against hypoxia/reoxygenation injury by alleviating er stress induced apoptosis in neonatal mouse cardiomyocytes. PLoS ONE 2015, 10, e0136443. [CrossRef] [PubMed]

(c) 2016 by the authors; licensee MDPI, Basel, Switzerland. This article is an open access article distributed under the terms and conditions of the Creative Commons by Attribution (CC-BY) license (http://creativecommons.org/licenses/by/4.0/). 